\title{
Cavitation study in bottom outlet gate slots by pressure fluctuation
}

\author{
Amir Khosrojerdi ${ }^{{ }^{*}}$, Elham Afkari Ahmad-Abad ${ }^{2}$ \\ ${ }^{1}$ Water Engineering Department, Science and Research Branch, Islamic Azad University, Tehran, Iran \\ ${ }^{2}$ Mathematics Department, Shahr-e - Ghoods Branch, Islamic Azad University, Tehran, Iran \\ khosrojerdi@srbiau.ac.ir, eafkari@yahoo.com
}

\begin{abstract}
Around the high head gates as the velocity is too high, every non uniform object such as a slot makes the flow too disturbed. Vertical-lift gate required recessed slots in abutments for the movement of the gate slides. The flow of water across the slots causes flow separation at the upstream lip of the slot and reattachment on the downstream side. Eddies are set up within the slots and vortices are formed. Thus, under higher velocity flow conditions (due to high head), cavitations can occur within gate slots by fluctuations. In addition of cavitations the pressure fluctuation can make impacts on the structure too. This hydraulic phenomenon can be occurred with serious damages. In this research, experimental data is used based on measuring pressure fluctuation by pressure transducer under an experimental model which has built and taken place in Michelle Hydraulics Laboratory at civil engineering department of the University of Melbourne. Pressure fluctuations were measured under two group of seven piezometers along the two gate slots for gate positions of 10\%-10\%, 30\%-10\%, 50\%-10\%, 70\%-10\%, 30\%-30\%, 50\%-30\%, 70\%-30\%, 50\%$50 \%, 70 \%-50 \%, 70 \%-70 \%$, head condition behind the gates were constant for all tests. The results were analyzed and presented as Cavitations Index in two slots. The cavitation indexes were calculated in based $0.1 \%$ probability levels of fluctuation pressures. Other probability levels contained 1\%, $5 \%$ as higher pressures and 95,99 and $99.9 \%$ as higher pressures, were studied in this paper.
\end{abstract}

Keywords: Cavitation, Bottom outlet gate, Pressure fluctuations, Slot .

\section{Introduction}

All around the world, the main damages in the bottom outlets are due to cavitations, erosion, vibration and crushing. For example, some of bottom outlets damaged by cavitations are Libby, Lucky Peak, Painted Rock, Dworshak, Stampede, Tarbela Glen Canton, Sefid-Rood, Jeeroft, and Masjed-Soleiman. Of course, before these damages occurred you can prevent the phenomenon by prediction of velocities and hydrodynamic pressures. Practically there are two high head gates in bottom outlet conduit of dams, the first one is the service gate for controlling the flow and the second gate (before service gate) is the emergency gate used when maintaining and repairing the service gate. Vertical-lift gate required recessed slots in abutments for the movement of the gate slides. The flow of water across the slots causes flow separation at the upstream edge of the slot and reattachment on the downstream side. Eddies are set up within the slots and vortices are formed. Under high velocity flow conditions (due to high head) some phenomenon probably occurs such as cavitations within the gate slots (Fiorotto \& Rinaldo, 1993; Amir Khosrojerdi, 2012). The flow passed from the gate slot, takes lower pressure and cavitations can occur within the slot or downstream of the slot when high velocity flow occurs and then there is insufficient pressure in the region of the slot. Cavitation in the slots was investigated by (Visher \& Hager, 1965) reviews cavitations in hydraulic structures and deals extensively with cavitations due to gate slots (Fiorotto \& Rinaldo, 1993). An important factor in pressure fluctuation is the conduit geometry downstream of the slot. The low pressure conditions on the downstream edge of the gate can be improved to some degree by offsetting the downstream edge of the slot and returning gradually to the original conduit wall alignment. (Visher \& Hagerl, 1965) showed deflectors at upstream edges of slots produce an ejector action which lowers pressures at the slot far below the reference pressure and will induce cavitations. A very large deflector which causes a heavy contraction can be used successfully. It is the basis of the jet-flow gates design. There is some basic information in the paper of ball which can be used as a guide for the design of gate slots. The upstream corners of the gate slots should not be rounded or notched as both are detrimental to pressure. Sharp downstream corners of gate slots should always be offset away from the flow. The offset of the downstream corner of a gate slot should be small and related to the slot width. Within reasonable limits, this offset is not critical. In this research, the slot geometries has been tried to follow the criteria The more fluctuation obtains the more disturbance and then structure faces in higher probability of cavitations and crush. Narayanan (1980) found the relationship between pressure fluctuations and cavitations in a stilling basin (Narayanan, 1980). Investigation of Lopardo et al. $(1982,1988)$ confirmed the Narayanan's research. They worked on a model and prototype of a stilling basin, so their results showed that in sever pressure fluctuations, cavitations is in higher probability, even if pressures have been happened more than vapor pressure (Lopardo et al., 1982; Lopardo, 1988). Also Narayanan (1984) did an experiment on a gate and its data showed that with more pressure fluctuation, more probability of cavitations will take place (Lopardo et al., 1982). Both Narayanan and Lopardo compared their data and reported that cavitations bubbles
Research article

(C)Indian Society for Education and Environment (iSee)
"Cavitation study"

http://www.indjst.org
Amir Khosrojerdi

Indian J.Sci.Technol. 
happening is related to the long time of fluctuation pressures which are lower than water vapor pressure, so that if in 0.2 percent of long time, the temporary pressures becomes less than water vapor pressure, the cavitations will take place. Blazjewski (1980), presented a formula that determine the minimum of the long time caused cavitations bubbles take place (Blazjewski, 1981). For reducing the risk of cavitations on chute spillway, Kavianpour $(1997,2000)$ suggested an aeration of more than 5 percent for cavitations area (Kavianpour, 1997 \& 2000). The more fluctuation obtains the more disturbance and then structure faces in higher probability of cavitations and crush. The pressure fluctuations make damage on the structures in two ways: 1- The pressures which are more than mean pressures, apply beats of pressures on the structures continually and in long time it makes the structure dissipated and crushed. 2- The pressures which are less than mean pressures, may apply cavitations as vacuum pressures.

\section{Experimental model}

In this research an experimental model was built and used. The measured data applied by pressure transducer are the fluctuation pressures in the slot column. Each date was taken in time range of 0.004 seconds, in other hand in one second there are 250 data for every piezometer in the slot. The pressure head behind of gate is fixed and approximately is equal to $2.6 \mathrm{~m}$. before using the transducer unit; it was calibrated by a column of scaled tube. On the slot's wall there are seven piezometer holes with uniform intervals together connected to transducer by 1 millimeter piezometer tubes. By this unit, the pressure fluctuations were measured for different openings of gate. The data have been analyzed by statistical techniques and cavitations indexes, pressure coefficients and several probability levels of pressures have been obtained. The model has been designed base on two gates. Cross section of conduit is square shape $(150 \mathrm{~mm} \times 150 \mathrm{~mm})$ and the thickness of gate is $30 \mathrm{~mm}$. The measurements in the model are done with respect to various opening gates $(10 \%-10 \%, 30 \%-$ $10 \%, 50 \%-10 \%, 70 \%-10 \%, 30 \%-30 \%, 50 \%-30 \%, 70 \%-$ $30 \%, 50 \%-50 \%, 70 \%-50 \%, 70 \%-70 \%$ ), the first numbers are related to downstream gate and second ones are related to upstream gate. The head behind the upstream gate is fixted equal to $2.6 \mathrm{~m}$. Measurement unit for measuring dynamic pressure is including pressure transducer sensor, amplifier, filter and data processor. The accessed transducer sensor can measure the pressure up to 0.35 bars. Data were taken in duration of 30 seconds.

\section{The measuring conditions}

According to Table 1 , there are 2 series of piezometer (from number 1 to 17) that measure the dynamic pressures in various points on the slots wall for opening of $10 \%-10 \%, 30 \%-10 \%, 50 \%-10 \%, 70 \%-10 \%, 30 \%-30 \%$, $50 \%-30 \%, 70 \%-30 \%, 50 \%-50 \%, 70 \%-50 \%, 70 \%-70 \%$.
Vol. 5 No. 3 (Mar 2012)

ISSN: 0974- 6846

Table 1. Piezometers conditions in gate slots
\begin{tabular}{|c|c|c|c|c|}
\hline & Piz No. & $\begin{array}{c}\mathrm{y}(\mathrm{cm}) \text { in } \\
\text { model }\end{array}$ & $\begin{array}{c}\mathrm{y}(\mathrm{m}) \text { in } \\
\text { Prototype }\end{array}$ & $\mathrm{y} / \mathrm{H}$ \\
\hline & 1 & 1 & 0.2 & 0.07 \\
\hline & 2 & 3 & 0.6 & 0.20 \\
\hline & 3 & 5 & 1 & 0.33 \\
\hline & 4 & 7 & 1.4 & 0.47 \\
\hline & 5 & 9 & 1.8 & 0.60 \\
\hline & 6 & 11 & 2.2 & 0.73 \\
\hline & 7 & 13 & 2.6 & 0.87 \\
\hline & 8 & 1 & 0.2 & 0.07 \\
\hline & 9 & 3 & 0.6 & 0.20 \\
\hline & 10 & 5 & 1 & 0.33 \\
\hline & 11 & 7 & 1.4 & 0.47 \\
\hline Downward Gate & 12 & 9 & 1.8 & 0.60 \\
\hline & 13 & 11 & 2.2 & 0.73 \\
\hline & 14 & 13 & 2.6 & 0.87 \\
\hline & 15 & 36 & 7.2 & 2.40 \\
\hline $\begin{array}{c}\text { Top of Chamber } \\
\text { in upward }\end{array}$ & 15 & & & \\
\hline $\begin{array}{c}\text { Top of Chamber } \\
\text { in Downward }\end{array}$ & 16 & 36 & 7.2 & 2.40 \\
\hline Top of inlet & 17 & 15 & 3 & 1.00 \\
\hline
\end{tabular}

Table 2. Flow conditions in different test stages

\begin{tabular}{|c|c|c|c|c|c|}
\hline Operation & $\begin{array}{c}\mathrm{Q}(\text { lit/s) in } \\
\text { model }\end{array}$ & $\begin{array}{c}\mathrm{Q}\left(\mathrm{m}^{3} / \mathrm{s}\right) \text { in } \\
\text { Prototype }\end{array}$ & $\begin{array}{c}\text { Head }(\mathrm{m}) \text { in } \\
\text { Prototype }\end{array}$ & Head/H & $\mathrm{Fr}$ \\
\hline $10 \%-10 \%$ & 10 & 17.9 & 58.7 & 19.6 & 11.6 \\
\hline $30 \%-10 \%$ & 11.5 & 20.6 & 58.9 & 19.6 & 13.3 \\
\hline $30 \%-30 \%$ & 38.6 & 69.0 & 56.9 & 19.0 & 8.6 \\
\hline $50 \%-10 \%$ & 12.2 & 21.8 & 52.6 & 17.5 & 14.1 \\
\hline $50 \%-30 \%$ & 38.1 & 68.2 & 51.8 & 17.3 & 8.5 \\
\hline $50 \%-50 \%$ & 66.4 & 118.8 & 50.7 & 16.9 & 6.9 \\
\hline $70 \%-10 \%$ & 12.2 & 21.8 & 52.7 & 17.6 & 14.1 \\
\hline $70 \%-30 \%$ & 37.2 & 66.5 & 55.2 & 18.4 & 8.3 \\
\hline $70 \%-50 \%$ & 70.8 & 126.7 & 48.5 & 16.2 & 7.3 \\
\hline $70 \%-70 \%$ & 101.2 & 181.0 & 42.9 & 14.3 & 6.3 \\
\hline $80 \%-70 \%$ & 95.6 & 171.0 & 43.8 & 14.6 & 6.0 \\
\hline
\end{tabular}

Every position of measurement points has showed as $\mathrm{y} / \mathrm{H}$ where $y$ is the distance of each point to conduit bottom and $\mathrm{H}$ is the height of conduit $(15 \mathrm{~cm}$ in model). Also Table 2 shows the flow conditions in basis of opening gates. In this table both model and prototype amounts are used in scale of 1:20. This scale is a selected assumption for recognizing better the dimension of the plan and cavitations index.

\section{Analyzing data}

Based on investigations on kinds of probability density function, the distribution of normal is a property method for prediction of pressures probability levels. In addition, the other researchers have found out the pressure fluctuation usually are followed by normal or Gauss's distributions too. According to the following equation, the normal function is based on mean pressure,

$$
P(z)=\frac{1}{\sqrt{2 \pi}} \exp \left[-\left(\frac{z^{2}}{2}\right)\right]
$$
and standard deviation $(\sigma, \bar{x})$.

where: 
$z=-\left(\frac{(x-\bar{x})^{2}}{2 \sigma^{2}}\right)$

By this equation we can drive the various probability levels of pressures occurred in the slots. These levels are usually considered $0.1,1,5,95,99$ and $99.9 \%$. The lower percentage (for lower pressures) is used in studying the cavitations and the higher percentage (for higher pressures) is used for impacting the flow on structures. Toso recommended the probability pressure of $1 \%$ for cavitations index (Toso \& Bowers, 1988). Also Lopardo (Lopardo et al., 1982; Lopardo, 1988) recommended the probability pressure of $0.1 \%$ for cavitations index. In this research the probability of $0.1 \%(\mathrm{P} \% 0.1)$ has been used for cavitations index. Thus the cavitations index, $\mathrm{C}_{\mathrm{v}}$ is presented as follow:

$$
C_{\mathrm{v}}=\frac{\mathrm{P}_{\% 0.1}-\mathrm{P}_{\mathrm{v}}}{V_{1}^{2} / 2 g}
$$

where $P_{v}$ is water vapor pressure.

The cavitations index, $C_{v}$ are driven from the measured data for various opening dates.

As previously stated the cavitations potential is predicted by cavitations index that involves the pressure probability of $0.1 \%$. In 10 opening gates, the cavitations indexes $\left(C_{v}\right)$ in 14 points in slots are calculated.

\section{Cavitation Index}

According to previous statements, the cavitation phenomenon is known by cavitation index. The index is calculated by the pressures with probability level of $0.1 \%$. The index in two slots (there are 7 pizometer points for each slot for measuring pressure fluctuations) has been calculated in eleven positions of two gates combination. The first slot is placed for upstream gate and second one is placed for downstream gate. Fig. 1 shows the minimum index e.g. 0.2 is related the conditions that the two gates position are similar (30\%-30\%, 50\%-50\%, 70\%-70\%). The similar gate positions mean water only impacts with first gates witout contact to second gate. This one gate system makes the flow lower disturbed. If cavitation criterion is considered 0.2 (the magore of references), in the upstream slot, cavitation isn't occurred in the all tests (according to Fig.1). It can be because the upstream slot is still overcome by the reservoir high head. In this research the main matter is variations kind of cavitation index and which factors make them increased or decreased.

According to Fig.2 and also Fig.4 (for more details), which show cavitation index in the downstream slot, the potential cavitation is high. Exception of gates positions of $30 \%-10 \%$ and $70 \%-10 \%$ that amounts of cavitation index are more than 20 and exception of gates position of $50 \%$ $10 \%$ that amounts of cavitation index is more than 5 , in the downstream slot, cavitation indexes are less than 1. Also for the gates positions that two gate have similar opening e.g $10 \%-10 \%, 30 \%-30 \%, 50 \%-50 \%$ and $70 \%-$
Vol. 5 No. 3 (Mar 2012)

ISSN: 0974- 6846

$70 \%$, the cavitation indexes are even less than 0.2 . This shows when the two gates are similar opening or downstream gate is more open than upstream gate (two gates are changed as one gate system), the cavitation potential in downstream slot is very high. Thus while operating gates we must try to avoid operating gates in one gate system.

Fig. 3 shows minimum cavitation index $(\mathrm{Cl})$ along the upstream slot and also downstream slot against opening two gates. In all conditions of opening gates the cavitation indexes related to upstream slot are more than down stream slot ones. This is because the disturbance due to upstream slot influences downstream slot flow and make

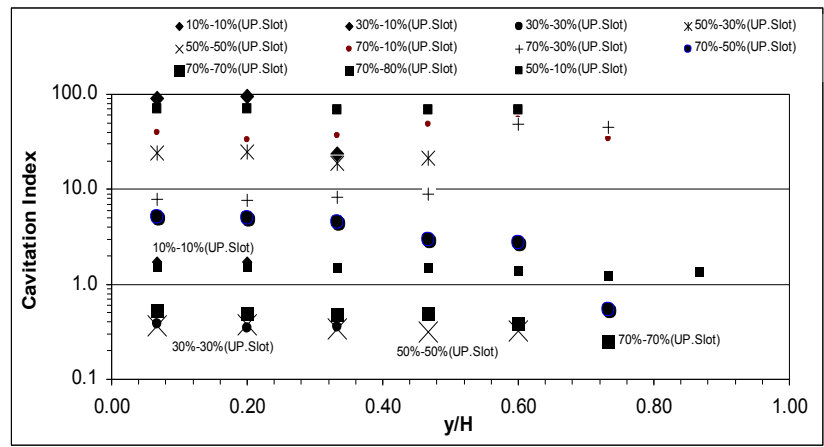

Fig. 1. Variation of Cavitation index along the upstream slot for various positions of gates.

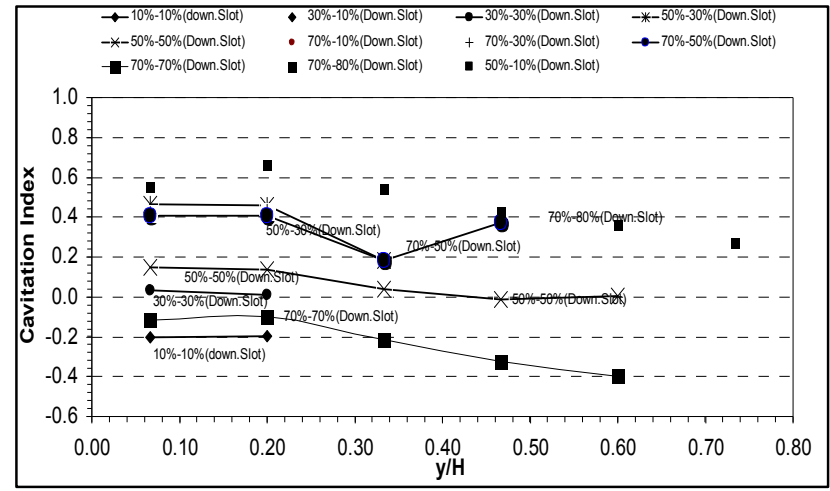

Fig 2. Variation of cavitation index along the downstream slot for various positions of gates.

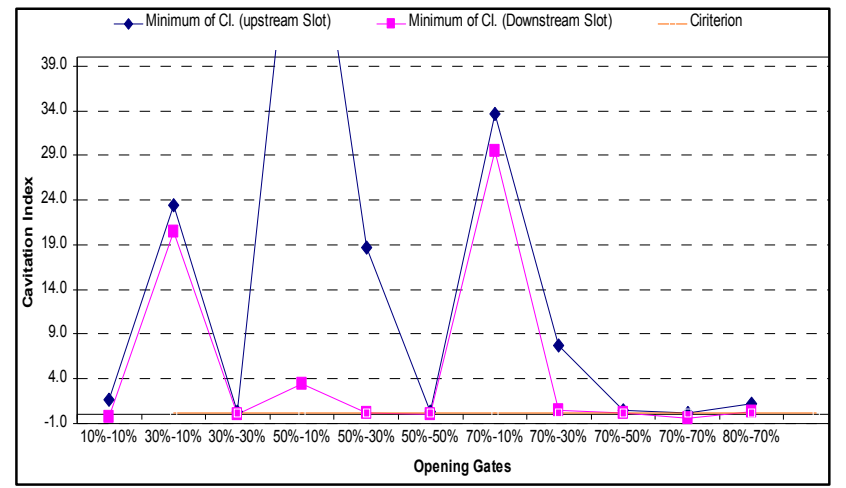

Fig 3. Comparisons of trend of minimume cavitation indexe (Cl.) for upstream slot and downstream slot. 


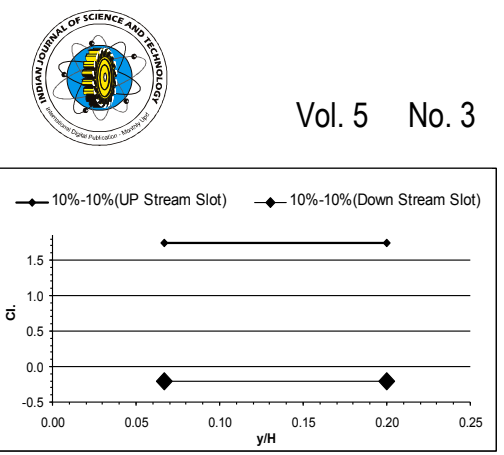

it more disturbance so that pressure in the downstream becomes lower. The criterion line if a horizontal line related to cavitation index equal 0.2 .

\section{Probabilities of pressures}

In addition to the probability of $0.1 \%$ for pressure, by the normal distribution, the other probabilities could be calculated (e.g. 1, 5, 95, 99, and $99.9 \%$ ). The pressures in various probability levels have been presented as dimensionless, $\mathrm{P}^{\prime} \%$ / RMS or P/RMS. Figs. 5 to 15 shows various P/RMS against $\mathrm{y} / \mathrm{H}$ in upstream and downstream slot separated by probability levels of $1,5,95,99$, $99.9 \%$. Each figure is made for a position of two gates. By reviewing the figures it's found out: In all gates positions and in all probability levels, the dimensionless pressures of upstream slot are bigger than downstream slot ones. Exception in the opening gate of $50 \%-30 \%, 70 \%-30 \%$ and $70 \%-50 \%$, all dimensionless pressure (P/RMS) distributions along the slots, are almost uniform. In gates position of $50 \%-30 \%$, in the downstream slot and next to $y / H=0.2$, with increasing the $y / H$, dimensionless pressure will decrease. In gates position of $70 \%-30 \%$, in the downstream slot and up to $\mathrm{y} / \mathrm{H}=0.2$, dimensionless pressure will increase and next to $\mathrm{y} / \mathrm{H}=0.2$, dimensionless pressure will decrease, while this decrease has a higher rate. Also In this position of gates, in upstream slot, up to $\mathrm{y} / \mathrm{H}=0.2$, dimensionless pressure will increase rapidly (about 100 changes) and between $\mathrm{y} / \mathrm{H}=0.2$ and $\mathrm{y} / \mathrm{H}=0.5$, there is a uniform changes and next to $y / H=0.5$, dimensionless pressure will decrease. The curves of these figures show that in downstream slot, the pressure distribution along slot is less uniform than upstream slot one.

In addition for comparing of dimensionless pressure distributions in upstream and downstream slot, according to Fig. 16, it has been used average of dimensionless pressures in every slot. According to previous statements, in all probability levels $(0.1,1,5,95,99,99.9 \%)$, dimensionless pressures mean in upstream slot is higher than downstream slot one. This difference is maximized in positions of $70 \%-30 \%$ and $70 \%$ $50 \%$ and minimize in position of $30 \%-10 \%$ and $50 \%-10 \%$.

\section{Results}

\section{Cavitation index}

1- Minimum cavitaion indexes that are between 0.2 to 1 , are belonged to the flows with similar gates position e.g. $30 \%-30 \%, 50 \%-50 \%$ and $70 \%-70 \%$ and also belonged to the positions which the downstream gate is equal or more open that upstream gate (one gate system). If the two gates are open differently e.g. the downstream gate becomes less open than

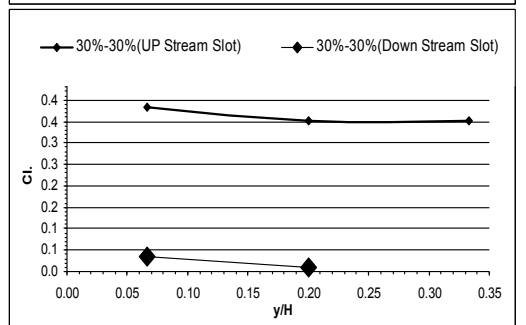

$\rightarrow$-50\%-50\%(UP Stream Slot) $\longrightarrow$ 50\%-50\%(Down Stream Slot)

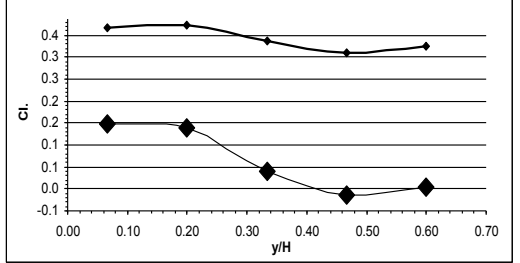

$\rightarrow-70 \%-10 \%$ (UP Stream Slot) $\rightarrow$ - 70\%-10\%(Down Stream Slot)

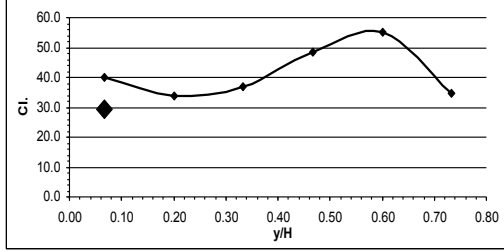

$\rightarrow-70 \%-50 \%$ (UP Stream Slot) $\rightarrow-70 \%-50 \%$ (Down Stream Slot)
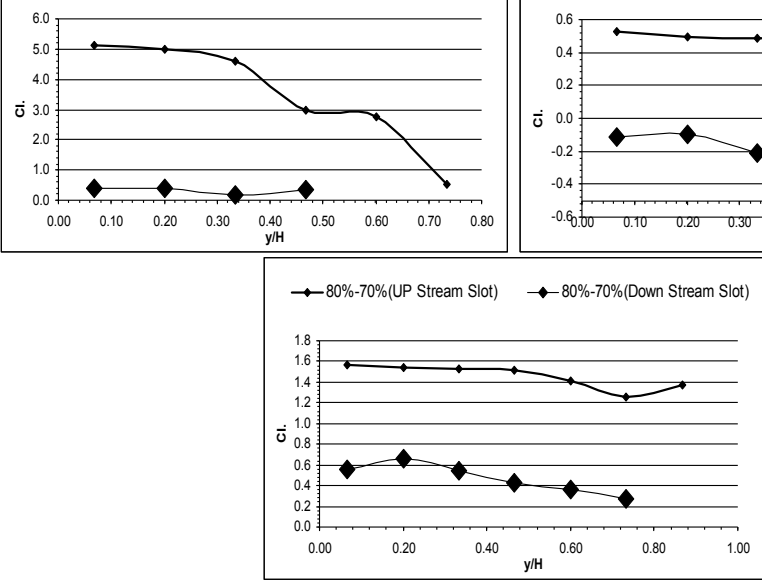

Fig 4. Variation of cavitation index along the downstream slot and upstream slot for various positions of gates.

upstream one (between two gates region will be filled with fluid), in the upstream slot the cavitation index will be more and cavitation potential will be less.

2- If criterion of cavitation index is defined by 0.2 , in the current test conditions that relative head is Head $/ \mathrm{H}=17.5$, in the upstream slot won't be taken
Research article

Clndian Society for Education and Environment (iSee)
Amir Khosrojerdi Indian J.Sci.Technol. 
Distribution of pressure along upstream and downstream slot with various probability levels for gates

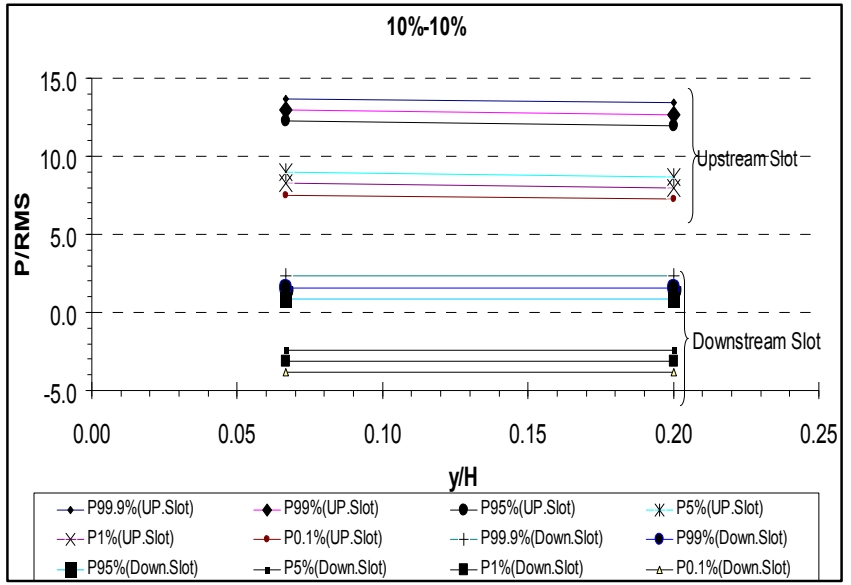

Fig. 5. Position of $10 \%-10 \%$.

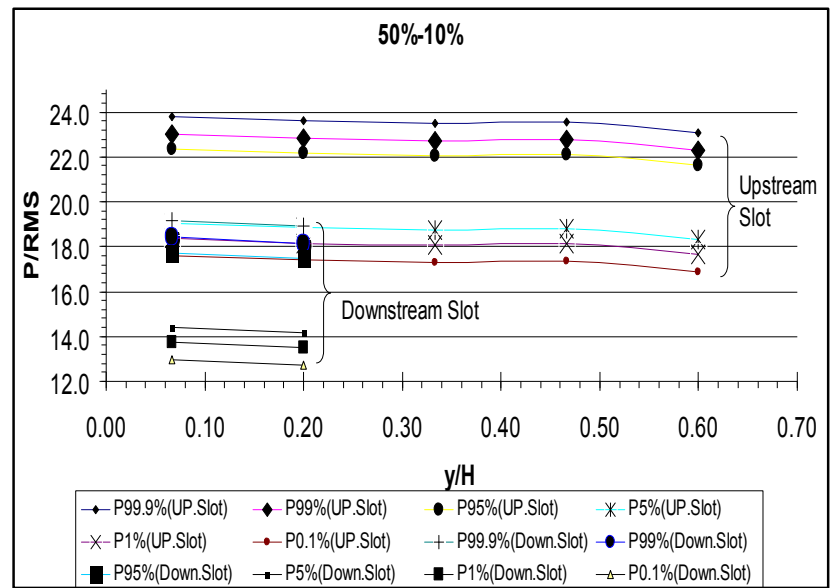

Fig. 8. Position of $50 \%-10 \%$.

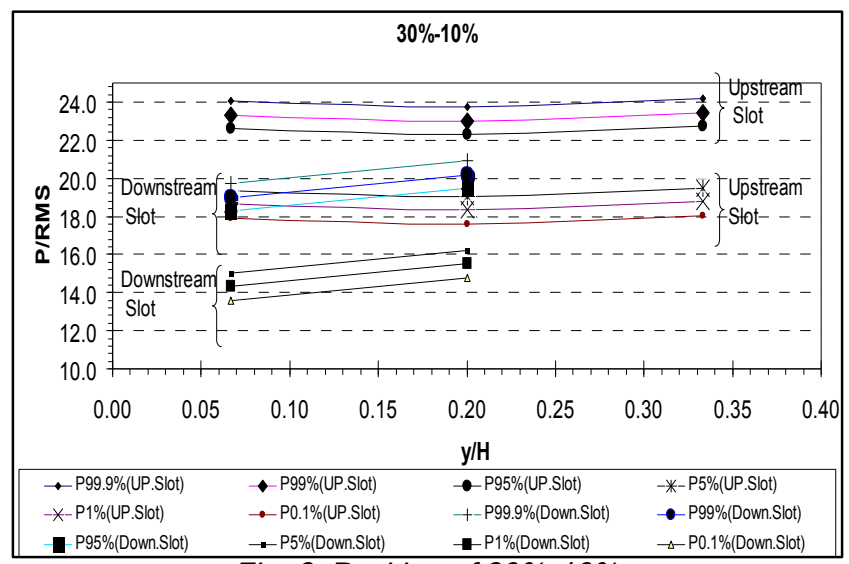

Fig. 6. Position of $30 \%-10 \%$.

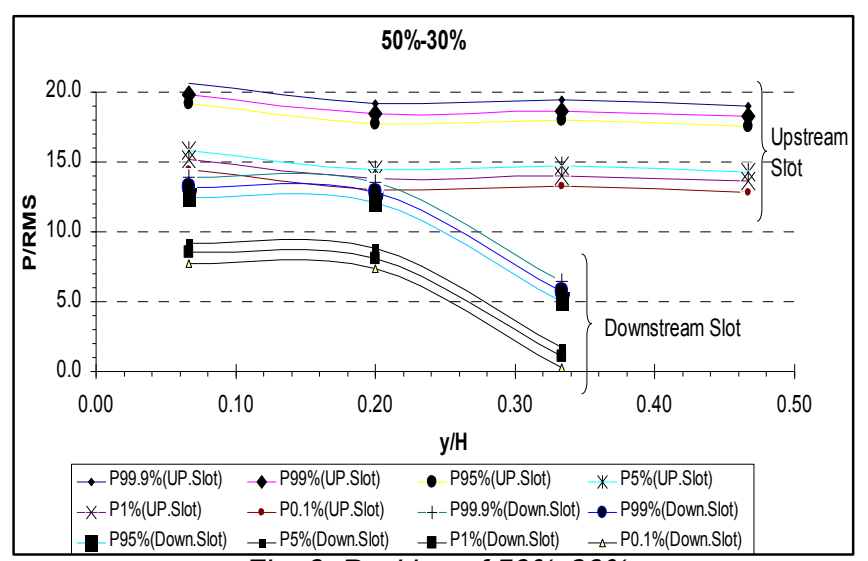

Fig. 9. Position of $50 \%-30 \%$

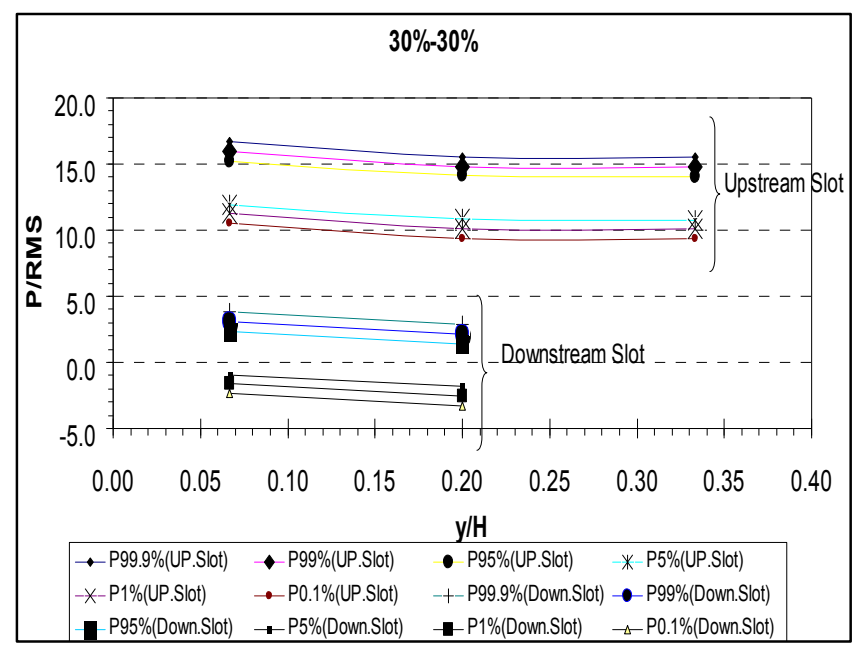

Fig. 7. Position of $30 \%-30 \%$.

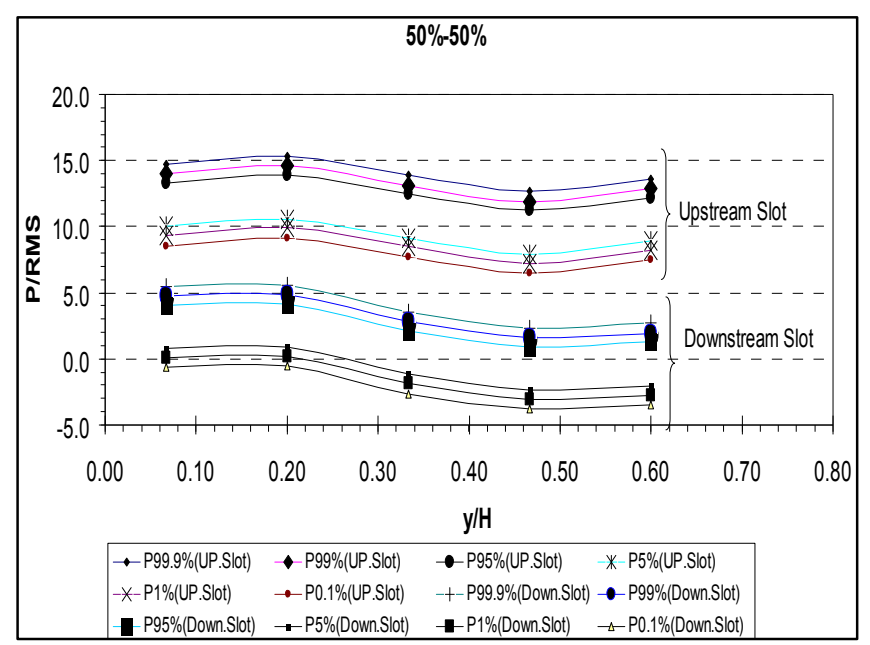

Fig. 10. Position of $50 \%-50 \%$.
Research article

Clndian Society for Education and Environment (iSee)
Amir Khosrojerdi Indian J.Sci.Technol. 
Distribution of pressure along upstream and downstream slot with various probability levels for gates

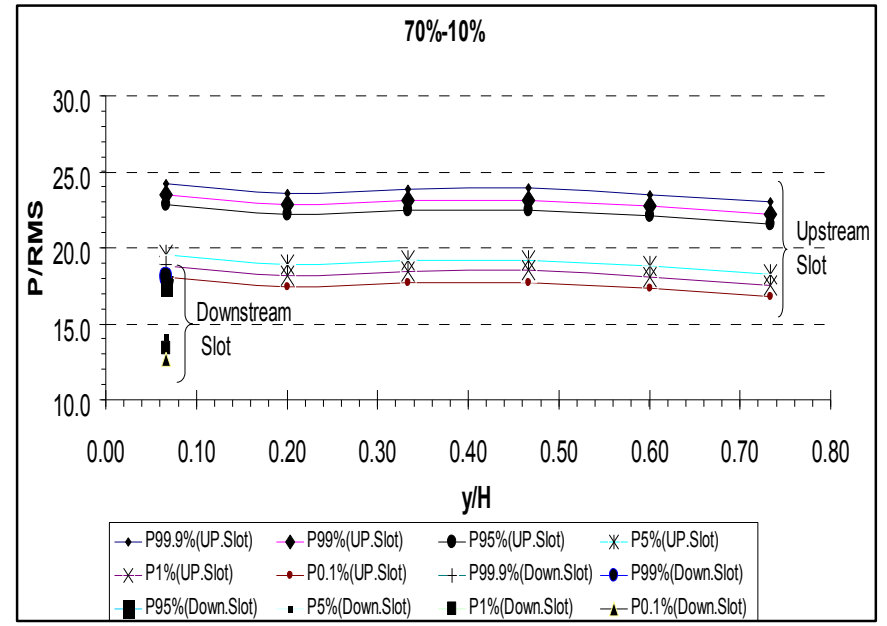

Fig. 11. Position of $70 \%-10 \%$.

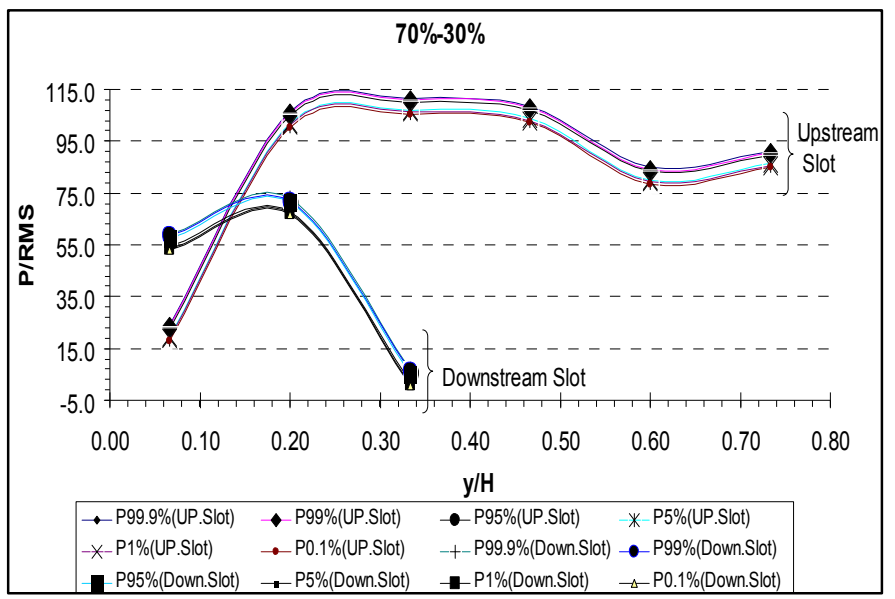

Fig. 12. Position of $70 \%-30 \%$.

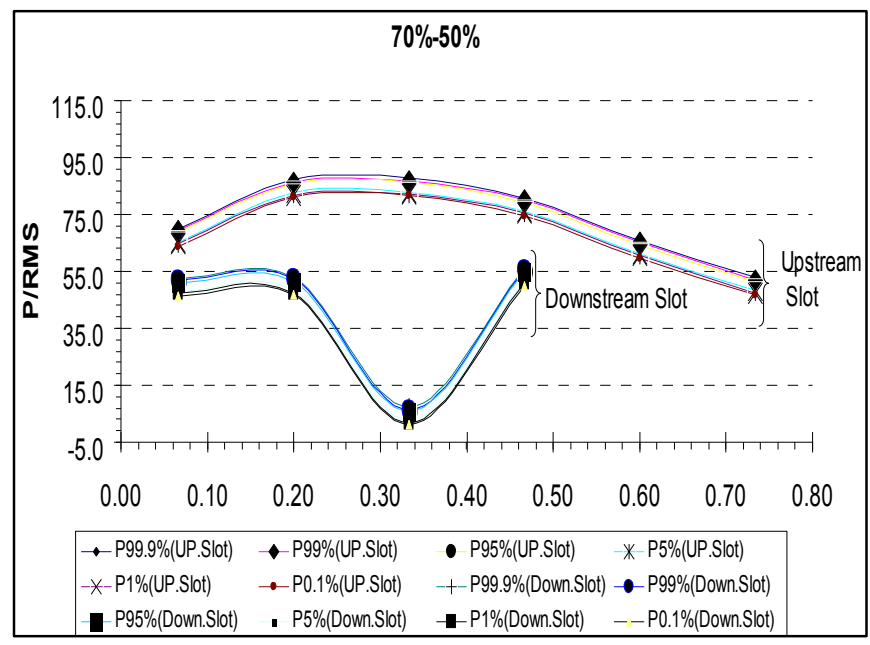

Fig. 13. Position of $70 \%-50 \%$.

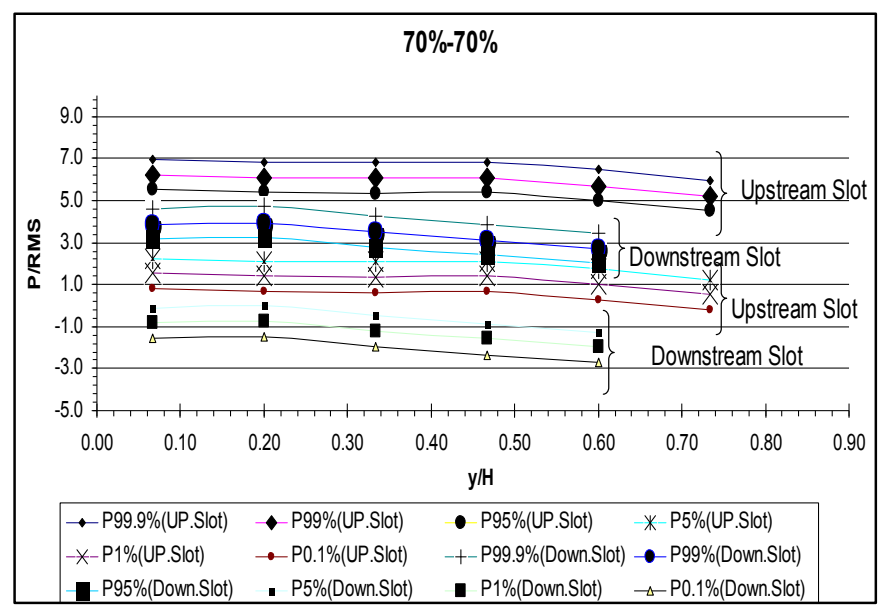

Fig. 14. Position of $70 \%-70 \%$.

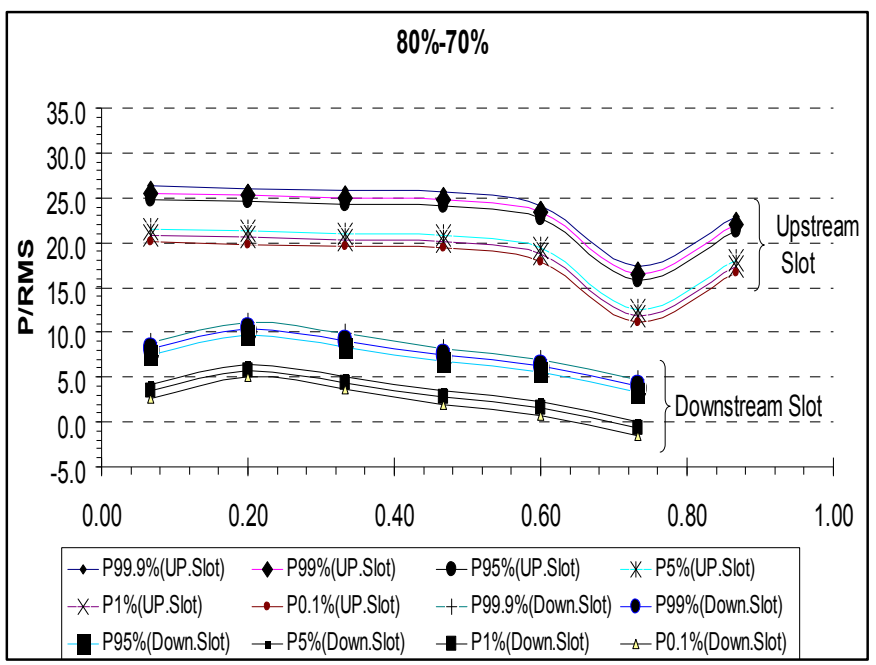

Fig. 15. Position of $80 \%-70 \%$.

Research article

CIndian Society for Education and Environment (iSee)
Amir Khosrojerdi Indian J.Sci.Technol. 
Vol. 5 No. 3 (Mar 2012)

ISSN: 0974- 6846

place cavitation. But an overview on the trend of cavitation indexes we can understand cavitation might occur in higher head $(\mathrm{Head} / \mathrm{H}>17.5)$ more for positions of one gate system $(30 \%-30 \%, 50 \%-50 \%$, 70\%-70\%).

3- The cavitation in the downstream slot is more probably than upstream slot. Exception of gates positions of $30 \%-10 \%$ and $70 \%-10 \%$ that amounts of cavitation index are more than 20 and exception of gates position of $50 \%-10 \%$ that amounts of cavitation index is more than 5 , in the downstream slot, cavitation indexes are less than 1 . Also for the gates positions that two gate have similar opening e.g $10 \%-10 \%, 30 \%-30 \%$, $50 \%-50 \%$ and $70 \%-70 \%$, the cavitation indexes are even less than 0.2 . This shows when the two gates are similar opening or downstream gate is more open than upstream gate (two gates are changed as one gate system), the cavitation potential in downstream slot is very high. Thus while operating gates we must try to avoid operating gates in one gate system.

4- In all conditions of opening gates the mean cavitation indexes along upstream slot are more than downstream slot ones. This is because the disturbance due to upstream slot influences downstream slot flow and make it more disturbance so that pressure in the downstream becomes lower.

Probabilities of pressures

1 - In all gates positions and in all probability levels $(0.1$, $1,5,95,99,99.9$ percents), the dimensionless pressures of upstream slot are bigger than downstream slot ones.

2- Exception in the opening gate of $50 \%-30 \%, 70 \%$ $30 \%$ and $70 \%-50 \%$, all dimensionless pressure (P/RMS) distributions along the slots, are almost uniform.

3- Exception in the opening gate of $30 \%-10 \%$ and $70 \%$ $70 \%$, in all positions of gates, dimensionless pressures in upstream slot even in probability levels of $0.1,1$ and $5 \%$ are bigger than downstream slot ones even in probability levels of 95,99 and $99.5 \%$.

4- In all probability levels $(0.1,1,5,95,99,99.9 \%)$, dimensionless pressures mean in upstream slot is higher than downstream slot one. This difference is maximized in positions of $70 \%-30 \%$ and $70 \%-50 \%$ and minimize in position of $30 \%-10 \%$ and $50 \%-10 \%$.

\section{Acknowledgment}

This study was sponsored by Civil \& environmental and chemical Engineering Department, the University of Melbourne. The writers thank Asc. Professor Roger Huges, Youshka shepherd, Tim Berrigan for their technical assistance and Dr. George Assaad and Professor. John D. Fenton for their scientific assistance.

Fig. 16. Comparison of dimensionless pressure in upstream and downstream slot for various probability levels.

Amir Khosrojerdi Indian J.Sci.Technol. 


\section{References}

1. Akbari ME, Mittal MK and Pande PK (1982) Pressure fluctuation on the floor of free forced hydraulic jump. Proc. Int. Conf. On the Hydraulic Modeling of Civil Eng. Struc., BHRA Fluid Engrg., Coventry, England, Paper C1, 87-96.

2. Amir Khosrojerdi (2012) Hydraulic studies of pressure distribution around vertical lift gates. Indian J.Sci. Technol. 5(3). (This issue)

3. Blazjewski R (1981) Cavitation induced by turbulence in stilling basin. Narayanan R. J. Hydraulic. Div. 107, 234-245.

4. Fiorotto $\vee$ and Rinaldo $A$ (1993) Turbulent pressure fluctuation under hydraulic jump, J. Hydraulic Res. 30(4), 499-520.

5. Kavianpour MR (1997) The reattaching flow downstream of deflector including the effect of air inject. A Thesis submitted to university of Manchester Institute of Science and Technology for the degree of Ph.D.

6. Kavianpour MR (2000) Effect of air on the structure of flow downstream of ramp. Proc. 4th. International Conference on Hydroscience Engineering, Seoul, Korea.

7. Lopardo RA (1988) Stilling Basin Pressure fluctuation. Int. Sym.on Model Prototype Correlation of Hydrraulic Structure ASCE, 56-73.

8. Lopardo RA, Delio JC and Vernet GF (1982) Physical modeling on cavitation tendency for macroturbulence of hydraulic jump. Proc., Int. Conf. on Hydraulic Modelling of Civil Eng. Struc., BHRA Fluid Engrs., Coventry ,England, Paper C3, 109-121.

9. Narayanan R (1980) Cavitations included by turbulence in stilling basin, J. Hydraulic Div. 106, 616619.

10. Toso and Bowers (1988) Extreme pressure in hydraulic jump stilling Basin. J. Hydraulic Eng. 114 (8), 829-843

11. Visher DL and Hager WH (1965) Energy dissipaters. Hydraulic structure design manual, IAHR, AA Balkema. Roterdam, Chap. 2 (pp:9-23), Chap. 7 (pp:111-115). 